PUBLIK: Jurnal Manajemen Sumber Daya Manusia, Adminsitrasi dan Pelayanan Publik Sekolah Tinggi Ilmu Administrasi Bina Taruna Gorontalo Volume VIII Nomor 1, 2021

\title{
PENGARUH PEMBERDAYAAN, LAMA MENGELOLA DAN PENDAPATAN TERHADAP KINERJA USAHA MIKRO, KECIL DAN MENENGAH (UMKM)
}

\author{
Suci Nur Indah Sari \\ Universitas Sarjanawiyata Tamansiswa \\ sucinurindahsarisnis21@gmail.com
}

\begin{abstract}
ABSTRAK
Penelitian ini bertujuan untuk menguji apakah pemberdayaan, lama mengelola dan pendapatan dapat mempengaruhi tingkat kinerja Usaha Mikro, Kecil dan Menengah (UMKM), khususnya pengusaha warung kelontong di Kecamatan Pleret Kabupaten Bantul.

Penelitian ini menggunakan data yang diambil dalam bentuk Data Primer yang diperoleh melalui kuesioner sebanyak 150 responden, dengansampel para pengusaha warung kelontong di Kecamatan Pleret Kabupaten Bantul. Teknik pengambilan sampel dengan menggunakan teknik Aksidental Sampeling, berdasarkan kebetulanyaitu siapa saja yang secara kebetulan/insidental bertemu dengan peneliti dapat digunakan sebagai sampel. Data dianalisis denganmenggunakanUji Validitas, Uji Reliabilitas, Uji Asumsi Klasik, Analisis Inferensial (Analisis Regresi Berganda), Koefisien Determinasi $\left(\mathrm{R}^{2}\right)$, dan Uji $\mathrm{T}$.

Hasil penelitian menunjukkan bahwa masing-masing variabel independen berpengaruh positif terhadap variabel dependen, yakni Pemberdayaan, Lama Mengelola dan Pendapatan berpengaruh secara positif dan signifikan terhadap Kinerja Usaha Mikro, Kecil dan Menengah (UMKM) yang ada di Kecamatan Pleret Kabupaten Bantul. Variabel yang paling dominan dalam penelitian ini adalah Pendapatan.

Kata Kunci: Pemberdayaan, Lama Mengelola, Pendapatan, Kinerja Usaha Mikro, Kecil dan Menengah (UMKM)
\end{abstract}

\begin{abstract}
This study aims to test whether empowerment, length of management and income can affect the level of performance of Micro, Small and Medium Enterprises (MSMEs), especially grocery shop entrepreneurs in Pleret District, Bantul Regency.

This study uses data taken in the form of primary data obtained through a questionnaire of 150 respondents, with a sample of grocery shop entrepreneurs in Pleret District, Bantul Regency. The sampling technique uses accidental sampling technique, based on coincidence, that is, anyone who accidentally / incidentally meets the researchers can be used as a sample. Data were analyzed using the Validity Test, Reliability Test, Classical Assumption Test, Inferential Analysis (Multiple Regression Analysis), Determination Coefficient (R2), and T Test.

The results showed that each independent variable had a positive effect on the dependent variable, namely empowerment, time to manage and income had a positive and significant effect on the performance of Micro, Small and Medium Enterprises (MSMEs) in Pleret District, Bantul Regency. The most dominant variable in this study is income.
\end{abstract}


PUBLIK: Jurnal Manajemen Sumber Daya Manusia, Adminsitrasi dan Pelayanan Publik Sekolah Tinggi Ilmu Administrasi Bina Taruna Gorontalo Volume VIII Nomor 1, 2021

\section{Keywords: Empowerment, Long Time to Manage, Income, Performance of Micro, Small and} Medium Enterprises (MSMEs)

\section{PENDAHULUAN}

Perkembangan ekonomi yang dilaksanakan secara bertahap, berencana dan berkesinambungan, pada dasarnya ditujukan untuk meningkatkan taraf hidup masyarakat. Tujuan pembangunan tersebut pada prinsipnya akantercapai apabila strategi pembangunan memadukan antara pencapaian pertumbuhan yang tinggi dengan terciptanya pemerataan pembangunan di segala bidang. Pemerataan pembangunan dapat diwujudkan dalam bentuk pemerataan lapangan kerja dan kesempatan berusaha sebagai usaha untuk menciptakan pemerataan pendapatan dan tentunya untuk keberlangsungan kesejahteraan usaha dan masyarakat.

Pembangunan di bidang sektor Usaha Mikro, Kecil dan Menengah (UMKM) merupakan salah satu cara untuk mencapai tujuan pembangunan nasional tersebut karena populasinya sangat besar dan memiliki peranan penting dalam perluasan lapangan kerja dan kesempatan berusaha. Sejak krisi moneter yang diawali tahun 1997-1998 hampir 80\% usaha besar mengalami kebangkrutan dan melakukan PHK masal terhadap karyawannya.Berbeda dengan Usaha Mikro, Kecil dan Menengah (UMKM) yang tetap bertahan di dalam krisis dengan segala keterbatasannya. Usaha Mikro, Kecil dan Menengah (UMKM) dianggap sektor usaha yang tidak cengeng dan tahan banting.

Pemberdayaan Usaha Mikro, Kecil dan Menengah (UMKM) merupakan bagian yang penting dalam pembangunan untuk mewujudkan masyarakat yangadil dan makmur.Pemberdayaan harus mampumembebaskan masyarakat dari kultural yangmenghambat usaha untuk berkembang.Faktor lain yang penting dalam menjalani usaha adalah lama mengelola, merupakan lama waktu yang sudah dijalani pedagang dalammenjalankan usahanya. Semakin lama seseorang dalam menekuni bekerjanya, maka Ia semakin berpengalaman, matang dan mahir dalam pekerjaan yang dipertranggungjawabkan kepadanya. Pendapatan juga jadi unsur yang sangat penting dalam sebuah usaha pertumbuhan ekonomi, karena dalam melakukan suatu usaha tentu ingin mengetahui nilai atau jumlah pendapatan yang diperoleh selama melakukan usaha tersebut.

Peranan Usaha Mikro, Kecil dan Menengah (UMKM) sangat penting dalam perluasan lapangan kerja dan kesempatan berusaha, namun masih banyak permasalahan dalam upaya pengembangan UMKM di Indonesia terkhususnya di Kecamatan Pleret Kabupaten Bantul. Di Kecamatan Pleret Kabupaten Bantul ini memiliki pengusaha warung kelontong dengan berbagai tingkat kinerja UMKM-nya. UMKM di daerah tersebut sudah 
PUBLIK: Jurnal Manajemen Sumber Daya Manusia, Adminsitrasi dan Pelayanan Publik Sekolah Tinggi Ilmu Administrasi Bina Taruna Gorontalo Volume VIII Nomor 1, 2021

cukup berjalan baik meskipun masih ditemukan permasalahan-permasalahan yang ada di lingkungan UMKM yang dihadapi para pelaku usaha, seperti masalah permodalan, masyarakat banyak yang mengeluhkan tentang terbatasnya modal, yang menyebabkan usaha mereka dari tahun ke tahun tidak berkembang menjadi lebih besar. Aparatur pemerintah yang kurang memperhatikan dan memberikan pembinaan (pemberdayaan) kepada masyarakat terhadap UMKM juga kurang memberikan pendampingan dan pelatihan kepada masyarakat, dan akses pengembangan Sumber Daya Manusia (SDM) untuk meningkatkan profesionalismeUMKM yang berdampak pada kinerja dan kesejahteraan UMKM.

Sasaran pembangunan UMKM di Kabupaten Bantul diarahkan pada pengembangan UMKM menjadi unit usaha yang kuat, maju, dan mandiri serta memiliki daya saing dengan fokus pada revitalisasi koperasi serta fasilitasi UMKM. Adapun sasarannya adalah peningkatan kinerja dan produktifitas UMKM. Secara umum perkembangan UKM di Kabupaten Bantul menunjukkan hal yang positif bagi peningkatan aktivitas perekonomian, pengentasan kemiskinan, dan mengurangi pengangguran.

Tabel 1

Pertumbuhan UKM Tahun 2013-2017

\begin{tabular}{|l|l|l|l|l|l|l|}
\hline No. & Uraian & $\mathbf{2 0 1 3}$ & $\mathbf{2 0 1 4}$ & $\mathbf{2 0 1 5}$ & $\mathbf{2 0 1 6}$ & $\mathbf{2 0 1 7}$ \\
\hline 1. & Jumlah UKM & 44.805 & 45.830 & 46.121 & 46.178 & 46.178 \\
\hline
\end{tabular}

Sumber: DKUKMP, 2018

Dari data Tabel 1 di atas, dapat dilihat bahwa pertumbuhan UKM di Kabupaten Bantul mengalami pertumbuhan yang signifikan, yaitu dari tahun 2013 sampai tahun 2017 pertumbuhannya sejumlah 1.373 unit usaha.

Adapun alasan yang mendorong ketertarikan peneliti untuk membahas ini yaitu keberadaan adanya pemberdayaan, lama mengelola dan pendapatan ternyata memberikan pengaruh yang berdampak kepada masyarakat sekitar untuk meningkatkan kinerja Usaha Mikro, Kecil dan Menengah (UMKM).

\section{METODE PENELITIAN}

Tujuan penelitian ini adalah untuk mengetahui pengaruh pemberdayaan, lama mengelola dan pendapatanterhadap kinerjaUsaha Mikro, Kecil Dan Menengah (UMKM) di Kecamatan Pleret Kabupaten Bantul, sehingga penelitian ini bersifat deskriptif kuantitaif yaitu penelitian dengan mendeskripsikan atau menggambarkan data yang telah terkumpul yang berwujud angka-angka atau menggunakan alat statistik (Sugiyono, 2017).

Dalam penelitian ini variabel independen yaitu pemberdayaan, lama mengelola dan pendapatan, sedangkan variabel dependen yaitu kinerja Usaha Mikro, Kecil Dan 
PUBLIK: Jurnal Manajemen Sumber Daya Manusia, Adminsitrasi dan Pelayanan Publik Sekolah Tinggi Ilmu Administrasi Bina Taruna Gorontalo Volume VIII Nomor 1, 2021

Menengah (UMKM). Pemberdayaan dapat diartikan sebagai upaya untuk meningkatkan kemampuan seseorang ataukelompok sehingga mampu melaksanakan tugas dan kewenangannya sebagaimana tuntutan kinerja tugas tersebut. (Andiny \& Nurjannah, 2018).

Indikator variabel independen Pemberdayaan menurut (SERAN et al., 2017) yaitu: 1) Kekuatan (Empowering), 2) Melindungi (Protecting), 3) Dukungan (Supporting), dan 4) Pengembangan (Fostering). Lama mengelola adalah semakin lama seseorang dalam menekuni bekerjanya, maka Ia semakin berpengalaman, matangdan mahir dalam pekerjaan yang dipertranggungjawabkan kepadanya (Polandos et al., 2019). Dalam arti ekonomi, pendapatan merupakan balas jasa atas penggunaan faktor-faktor produksi yang dimiliki oleh sektor rumah tangga dan sektor perusahaan yang dapat berupa gaji/upah, sewa, bunga serta keuntungan/profit (Maheswara et al., 2016). Ketika orang-orang menikmati suatu bentuk pendapatan, mereka akan mampu (secara relatif) membeli beberapa hal mendasar kebutuhan hidup (makanan, sandang, papan dan perawatan kesehatan). Dengan demikian UMKM membantu pengentasan kemiskinan. (Agyapong, 2010)

Populasi dalam penelitian ini yaitu pengusaha warung kelontong yang ada di wilayah Kecamatan Pleret Kabupaten Bantul. Sampel dalam penelitian ini adalah sebagian pengusaha warung kelontong yang berada di wilayah Kecamatan Pleret Kabupaten Bantul. Karena jumlah anggota populasi tidak diketahui maka pengambilan sampel menggunakan rumus Metode Jumlah Pertanyaan, yaitu melalui jumlah item-item pertanyaan pada kuesioner. Caranya, mengalikan 5X jumlah item pertanyaan (Wiyono, 2011). Maksudnya adalah jumlah variabel dikali jumlah item pertanyaan.

Berdasarkan cara tersebut, maka 4 X 28 pertanyaan = 112 sampel. Maka diperoleh hasil jumlah sampel minimal yang dibutuhkan dalam penelitian ini adalah 112 responden. Pada penelitian ini menggunakan 150 responden. Dalam penelitian ini teknik pengambilan sampel dengan menggunakan caranon probability sampling dengan teknik Aksidental Sampeling.

Pengumpulan data pada penelitian ini dengan menggunakan instrumen kuesioner, yaitu teknik pengumpulan data dan informasi dengan cara mengedarkan daftar pertanyaan kepada rsponden yang diteliti dan menggunakan aplikasi Google Form.

\section{HASIL PEMBAHASAN}

\section{Uji Validitas}

Untuk menguji derajat kebebasan $\mathrm{df}=\mathrm{n}-\mathrm{k}(\mathrm{df}=150-2=148)$ diperoleh $\mathrm{r}$ tabel sebesar 0.1603 dengan uji satu arah, diperoleh melalui = B3/SQRT(A3+B3^2). Untuk r tiap butir dapat dilihat pada kolom (Corrected item total correlation). Hasil Uji Validitas dapat ditunjukkan pada tabel berikut: 
PUBLIK: Jurnal Manajemen Sumber Daya Manusia, Adminsitrasi dan Pelayanan Publik Sekolah Tinggi Ilmu Administrasi Bina Taruna Gorontalo Volume VIII Nomor 1, 2021

\begin{tabular}{|c|c|c|c|c|}
\hline \multicolumn{5}{|c|}{$\begin{array}{c}\text { Tabel } 2 \\
\text { Hasil Uji Validitas Pemberdayaan }\end{array}$} \\
\hline Variabel & Butir & r hitung & $r$ tabel & Keterangan \\
\hline \multirow{8}{*}{ Pemberdayaan } & PM1 & $0,499^{\star *}$ & 0,160 & Valid \\
\hline & PM2 & $0,530^{\star *}$ & 0,160 & Valid \\
\hline & PM3 & $0,542^{\star *}$ & 0,160 & Valid \\
\hline & PM4 & $0,584^{\star *}$ & 0,160 & Valid \\
\hline & PM5 & $0,566^{* *}$ & 0,160 & Valid \\
\hline & PM6 & $0,460^{* *}$ & 0,160 & Valid \\
\hline & PM7 & $0,653^{\star *}$ & 0,160 & Valid \\
\hline & PM8 & $0,565^{\star \star}$ & 0,160 & Valid \\
\hline \multirow{6}{*}{ Lama Mengelola } & LM1 & $0,649^{\star \star}$ & 0,160 & Valid \\
\hline & LM2 & $0,600^{\star *}$ & 0,160 & Valid \\
\hline & LM3 & $0,585^{\star \star}$ & 0,160 & Valid \\
\hline & LM4 & $0,524^{\star \star}$ & 0,160 & Valid \\
\hline & LM5 & $0,455^{\star \star}$ & 0,160 & Valid \\
\hline & LM6 & $0,607^{\star \star}$ & 0,160 & Valid \\
\hline \multirow{4}{*}{ Pendapatan } & PN1 & $0,694^{\star *}$ & 0,160 & Valid \\
\hline & PN2 & $0,720^{\star *}$ & 0,160 & Valid \\
\hline & PN3 & $0,743^{\star *}$ & 0,160 & Valid \\
\hline & PN4 & $0,728^{\star *}$ & 0,160 & Valid \\
\hline \multirow{10}{*}{ Kinerja UMKM } & KU1 & $0,736^{\star *}$ & 0,160 & Valid \\
\hline & KU2 & $0,509^{* *}$ & 0,160 & Valid \\
\hline & KU3 & $0,635^{\star \star}$ & 0,160 & Valid \\
\hline & KU4 & $0,548^{* *}$ & 0,160 & Valid \\
\hline & KU5 & $0,385^{\star *}$ & 0,160 & Valid \\
\hline & KU6 & $0,504^{\star \star}$ & 0,160 & Valid \\
\hline & KU7 & $0,733^{\star *}$ & 0,160 & Valid \\
\hline & KU8 & $0,561^{\star *}$ & 0,160 & Valid \\
\hline & KU9 & $0,619^{\star *}$ & 0,160 & Valid \\
\hline & KU10 & $0,655^{\star *}$ & 0,160 & Valid \\
\hline
\end{tabular}

Hasil perhitungan Koefisien Korelasi seluruhnya mempunyai $r$ hitung yang lebih besar dari $\mathrm{r}$ tabel ( $\mathrm{r}$ hitung $>\mathrm{r}$ tabel). Dengan demikian, dapat disimpulkan bahwa seluruh butir dinyatakan Valid dan seluruh butir pertanyaan yang ada pada instrumen penelitian dapat dinyatakan layak sebagai instrumen untuk mengukur data penelitian.

\section{Uji Reliabilitas}

Hasil Uji Reliabilitas ini dilakukan dengan Uji Cronbach's Alpha Based on Standaridized items, dengan nilai Cronbach's Alpha Based> 0,60. Maka instrumen tersebut dikatakan haldal (Reliabel). Berdasarkan pada Tabel 3 menunjukkan bahwa masing-masing kuesioner memiliki koefisien reliabilitas lebih besar dari 0,60. 
PUBLIK: Jurnal Manajemen Sumber Daya Manusia, Adminsitrasi dan Pelayanan Publik Sekolah Tinggi Ilmu Administrasi Bina Taruna Gorontalo Volume VIII Nomor 1, 2021

Tabel 3

Hasil Uji Reliabilitas

\begin{tabular}{lccc}
\hline \multicolumn{1}{c}{ Variabel } & Cronbach's Alpha & Nilai Kritis & Keterangan \\
\hline Pemberdayaan & 0,666 & 0,60 & Reliabel \\
Lama Mengelola & 0,572 & 0,60 & Reliabel \\
Pendapatan & 0,693 & 0,60 & Reliabel \\
KinerjaUMKM & 0,744 & 0,60 & Reliabel \\
\hline
\end{tabular}

\section{Uji Asumsi Klasik}

\section{a. Uji Normalitas}

Gambar 1 grafik Normal Probability Plot pada persamaan Uji Normalitas Hipotesis 1, 2, dan 3 menunjukkan bahwa gambar data atau titik menyebar di garis diagonal dan mengikuti arah garis diagonal, maka dapat disimpulkan bahwa data-data tersebut berdistribusi normal dan konsisten.

\section{Normal P-P Plot of Regression Standardized Residual}

\section{Dependent Variable: Kesejahteraan Masyarakat}

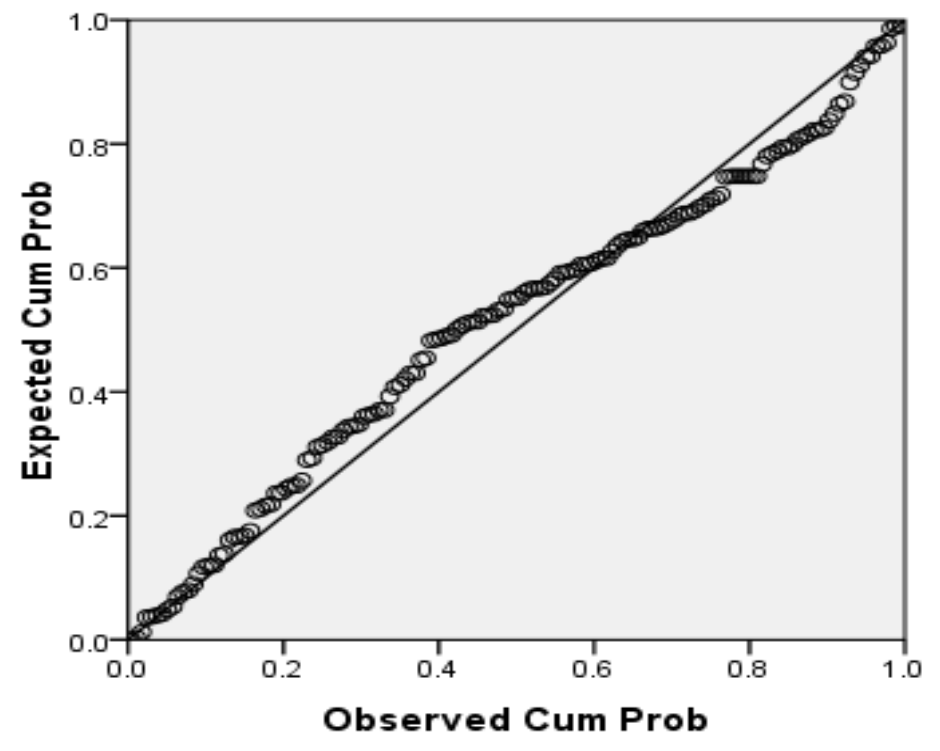

Gambar 1

Hasil Uji Normalitas Probability Plot 
PUBLIK: Jurnal Manajemen Sumber Daya Manusia, Adminsitrasi dan Pelayanan Publik Sekolah Tinggi Ilmu Administrasi Bina Taruna Gorontalo Volume VIII Nomor 1, 2021

\section{Tabel 4}

\section{Hasil Uji Normalitas Data Kolmogorov-Smirnov}

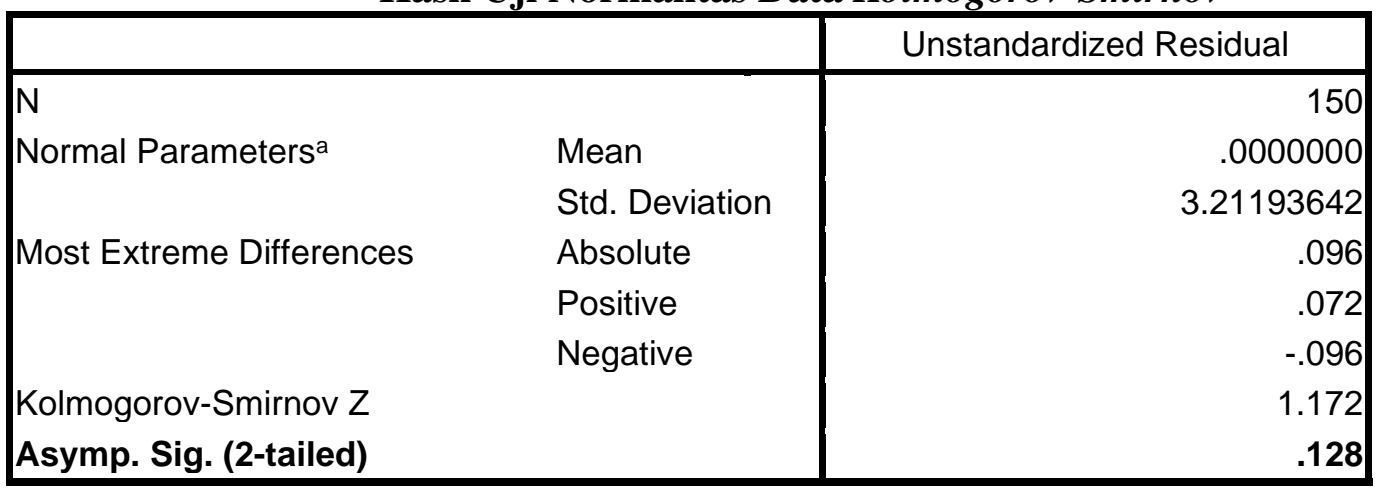

a. Test distribution is Normal.

b. Calculated from data.

Berdasarkan hasil Uji Normalitas Data Kolmogorov-Smirnov tersebut, maka dapat dinyatakan bahwa data-data tersebut berdistribusi normal, dikarenakan Asymp. Sig. (nilai signifikansi) > 0,05, yaitu $\mathbf{0 , 1 2 8}>\mathbf{0 , 0 5}$.

\section{b. Uji Multikolonieritas}

\section{Tabel 5}

\section{Hasil Uji Multikolonieritas} Coefficients $^{a}$

\begin{tabular}{|ll|r|r|r|c|}
\hline & & & \multicolumn{2}{|c|}{ Collinearity Statistics } \\
\cline { 5 - 6 } Model & & $\mathrm{t}$ & Sig. & Tolerance & \multicolumn{1}{c|}{ VIF } \\
\hline 1 & (Constant) & 2.013 & .046 & & \\
& Pemberdayaan & 1.985 & .049 & .772 & $\mathbf{1 . 2 9 5}$ \\
& Lama Mengelola & 2.587 & .011 & .648 & $\mathbf{1 . 5 4 4}$ \\
& Pendapatan & 5.989 & .000 & .650 & $\mathbf{1 . 5 3 9}$ \\
\hline
\end{tabular}

a. Dependent Variable: KinerjaUMKM

Dari Tabel 5 di atas dapat diketahui nilai Variance InflactionFactor (VIF) ketiga variabel yakni Pemberdayaan =1,295, Lama Mengelola= 1,544, dan Pendapatan $=1,5391$ ebih kecil dari 5, sehingga dapat disimpulkan bahwa antar variabel independen tidak terjadi masalah Multikolinearitas.

Sedangkan nilai Tolerance dari ketiga variabel yakni Pemberdayaan $=0,772$, Lama Mengelola $=0,648$, dan Pendapatan $=0,650$ lebih besar dari 0,10 sehingga dapat disimpulkan bahwa antar variabel independen tidak terjadi masalah Multikolinearitas. 


\section{c. Uji Heterokesdastisitas}

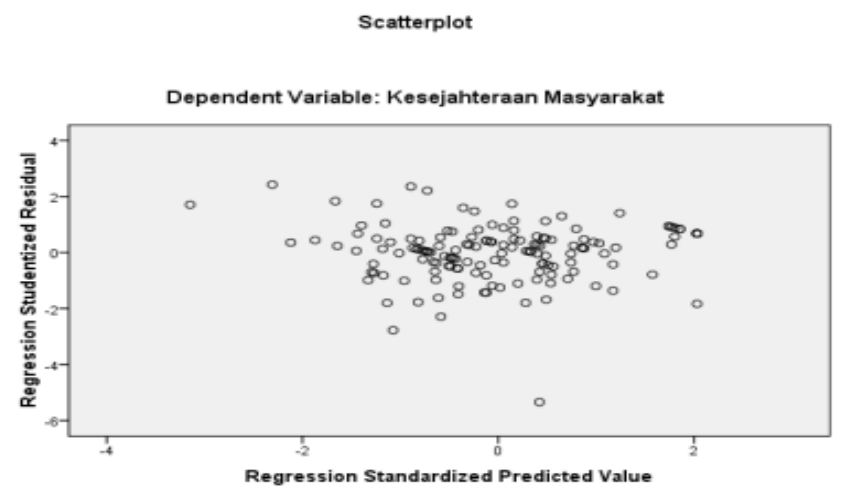

Gambar 2

Hasil Uji Heterokesdastisitas Scatterplot

Dari Gambar 2 Output Scatterplot diatas, terlihat titik-titik menyebar secara acak, tidak membentuk pola tertentu yang jelas, serta tersebar baik diatas maupun dibawah angka 0 pada sumbu Y. Dapat disimpulkan variabel bebas diatas tidak terjadi Heterokedastisitas.

\section{Analisis Regresi Linier}

Metode analisis data yang digunakan dalam penelitian ini adalah sebagai berikut:

a. Analisis Inferensial

Tabel 6

Hasil Analisis Regresi Berganda Coefficients $^{\mathrm{a}}$

\begin{tabular}{|ll|r|r|r|}
\hline \multirow{2}{*}{ Model } & & \multicolumn{2}{|c|}{$\begin{array}{c}\text { Unstandardized } \\
\text { Coefficients }\end{array}$} & $\begin{array}{c}\text { Standardized } \\
\text { Coefficients }\end{array}$ \\
\cline { 2 - 5 } & \multicolumn{1}{|c|}{ B } & Std. Error & \multicolumn{1}{c|}{ Beta } \\
\hline 1 & (Constant) & $\mathbf{9 . 0 1 9}$ & 4.481 & \\
& Pemberdayaan & .251 & .126 & .139 \\
& Lama Mengelola &. $\mathbf{4 0 5}$ & .157 & .198 \\
& Pendapatan &. $\mathbf{8 3 2}$ & .139 & .458 \\
\hline
\end{tabular}

a. Dependent Variable: Kinerja UMKM

Berdasarkan data Tabel 6, dapat diperoleh persamaan regresisebagai berikut :

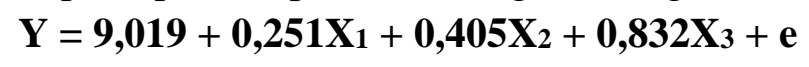

Pada persamaan diatas, menunjukkan adanya pengaruh positif variabel bebas yaitu Pemberdayaan (X1), Lama Mengelola (X2), dan Pendapatan(X3) terhadap variabel terikat yaitu KinerjaUMKM (Y). 
PUBLIK: Jurnal Manajemen Sumber Daya Manusia, Adminsitrasi dan Pelayanan Publik Sekolah Tinggi Ilmu Administrasi Bina Taruna Gorontalo Volume VIII Nomor 1, 2021

Tabel 6diatas menunjukkan variabel yang paling dominan yang dapat dilihat dari kolom Unstandarized Coefficients B, kolom tersebut menunjukkan bahwa Pendapatan (X3) memiliki angka yang paling tinggi $(0,832)$ dibandingkan dengan variabel lain.

\section{b. Analisis Koefisien Determinasi $\left(\mathbf{R}^{2}\right)$}

\section{Tabel 7}

Hasil Koefisien Determinasi (R2) Model Summary

\begin{tabular}{|l|r|r|r|r|}
\hline Model & $\mathrm{R}$ & $\mathrm{R}$ Square & Adjusted R Square & $\begin{array}{c}\text { Std. Error of the } \\
\text { Estimate }\end{array}$ \\
\hline 1 & $.668^{\mathrm{a}}$ & .446 & .434 & 3.245 \\
\hline
\end{tabular}

a. Predictors: (Constant), Pendapatan, Pemberdayaan, Lama Mengelola

Dari Tabel 7 diketahui bahwa variabel independen mempengaruhi variabel dependen sebesar 0,434 dilihat dari kolom Adjusted $R$ Square. Hal ini dapat disimpulkan bahwa variabel independen Pemberdayaan (X1), Lama Mengelola (X2), dan Pendapatan (X3) yang berpengaruh terhadap variabel dependen Kinerja UMKM (Y)sebesar 43,4\% dan sisanya 56,6\% dipengaruhi oleh variabel lain.

\section{c. Hasil Uji T}

Dalam penelitian ini memiliki 3 Hipotesis yang diuji untuk melihat pengaruh Pemberdayaan (PM), Lama Mengelola (LM), dan Pendapatan (PN) terhadap Kinerja UMKM (KU). 3 Hipotesis ini diuji menggunakan Analisis Uji Signifikansi Parameter Individual (Uji t).

$$
\mathrm{t} \text { tabel }=\mathrm{t}(\mathrm{a} / 2 ; \mathrm{n}-\mathrm{k}-1)=\mathrm{t}(0,05 / 2 ; 150-3-1)=\mathrm{t}(0,025 ; 146)=1,976
$$

Dimana :

$$
\begin{aligned}
& \mathrm{a}=\text { Tingkat kepercayaan }=>0,05 \\
& \mathrm{n}=\text { Jumlah sampel }=>150 \\
& \mathrm{k}=\text { Variabel } \mathrm{X}=>3
\end{aligned}
$$


PUBLIK: Jurnal Manajemen Sumber Daya Manusia, Adminsitrasi dan Pelayanan Publik

Sekolah Tinggi Ilmu Administrasi Bina Taruna Gorontalo Volume VIII Nomor 1, 2021

Tabel 8

Hasil Uji T

Coefficients $^{\mathrm{a}}$

\begin{tabular}{|c|c|c|c|c|c|}
\hline \multirow[b]{2}{*}{ Model } & \multicolumn{2}{|c|}{$\begin{array}{l}\text { Unstandardized } \\
\text { Coefficients }\end{array}$} & \multirow{2}{*}{\begin{tabular}{|c|}
$\begin{array}{c}\text { Standardize } \\
\mathrm{d} \\
\text { Coefficients }\end{array}$ \\
Beta
\end{tabular}} & \multirow[b]{2}{*}{$t$} & \multirow[b]{2}{*}{ Sig. } \\
\hline & B & Std. Error & & & \\
\hline (Constant) & 9.019 & 4.481 & & 2.013 & .046 \\
\hline Pemberdayaan & 251 & .126 & -139 & 1.985 & .049 \\
\hline Lama Mengelola & .405 & .157 & .198 & 2.587 & 011 \\
\hline Pendapatan & .832 & .139 & .458 & 5.989 & .000 \\
\hline
\end{tabular}

a. Dependent Variable: KinerjaUMKM

Tabel 8 dapat dijelaskan sebagai berikut:

1) Pengujian Hipotesis 1

Hipotesis 1 atau Ha Ada pengaruh positif dan signifikan pemberdayaan terhadap kinerja UMKM yang ada di Kecamatan Pleret Kabupaten Bantul. Berdasarkan hasil Tabel 8 variabel Pemberdayaan memiliki t hitung $>\mathrm{t}$ tabel yakni sebesar 1,985> 1,976 dan signifikansi 0,049<0,05. Sehingga dapat disimpulkan bahwa H1 (Ha) diterima dan Ho ditolak, yang berarti terdapat pengaruh variabel Pemberdayaan (X1) terhadap Kinerja UMKM (Y).

2) Pengujian Hipotesis 2

Hipotesis 2 atau $\mathrm{Ha}$ Ada pengaruh positif dan signifikan lama mengelola terhadap kinerja UMKM yang ada di Kecamatan Pleret Kabupaten Bantul. Berdasarkan hasil Tabel 8 variabel Lama Mengelola memiliki t hitung $>\mathrm{t}$ tabel yakni sebesar 2,587> 1,976 dan signifikansi 0,011<0,05. Sehingga dapat disimpulkan bahwa $\mathrm{H} 2$ (Ha) diterima dan Ho ditolak, yang berarti terdapat pengaruh variabel Lama Mengelola (X2) terhadap Kinerja UMKM (Y).

3) Pengujian Hipotesis 3

Hipotesis 3 atau Ha Ada pengaruh positif dan signifikan pendapatan terhadap kinerja UMKM yang ada di Kecamatan Pleret Kabupaten Bantul. Berdasarkan hasil Tabel 8 variabel Pendapatan memiliki t hitung > t tabel yakni sebesar 5,989> 1,976 dan signifikansi $0,000<0,05$. Sehingga dapat disimpulkan bahwa H3 (Ha) diterima dan Ho ditolak, yang berarti terdapat pengaruh variabel Pendapatan (X3) terhadap Kinerja UMKM (Y).

Sebagai hasil penelitian, telah dilakukan analisa data dengan menggunakan metode statistik, maka dapat dideskripsikan hasil penelitian sebagai berikut: 
PUBLIK: Jurnal Manajemen Sumber Daya Manusia, Adminsitrasi dan Pelayanan Publik Sekolah Tinggi Ilmu Administrasi Bina Taruna Gorontalo Volume VIII Nomor 1, 2021

1. Dari hasil Analisis Regresi Linier dalam penelitian ini menunjukkan bahwa variabel independen mempengaruhi variabel dependen sebesar 0,434 dilihat dari kolom Adjusted $R$ Square. Hal ini dapat disimpulkan bahwa variabel independen Pemberdayaan (X1), Lama Mengelola (X2), dan Pendapatan (X3) yang berpengaruh terhadap variabel dependen Kinerja UMKM (Y) sebesar 43,4\% dan sisanya 56,6\% dipengaruhi oleh variabel lain.

2. Berdasarkan data Tabel 6 , dapat diperoleh persamaan regresi sebagai berikut:

$$
\mathbf{Y}=\mathbf{9 , 0 1 9}+\mathbf{0 , 2 5 1 X 1}+\mathbf{0 , 4 0 5 X 2}+\mathbf{0 , 8 3 2 X 3}+\mathrm{e}
$$

Pada persamaan di atas, menunjukkan adanya pengaruh positif variabel bebas yaitu Pemberdayaan (X1) yakni sebesar 0,251, Lama Mengelola (X2) sebesar 0,405, dan Pendapatan (X3) sebesar 0,832 terhadap variabel terikat yaitu Kinerja UMKM (Y).

3. Berikut ini adalah pengaruh antar variabel independen dan dependen, yang terdiri dari Pemberdayaan, Lama Mengelola, Pendapatan, dan Kinerja Usaha Mikro, Kecil dan Menengah (UMKM):

a. Pengaruh Pemberdayaan Terhadap Kinerja Usaha Mikro, Kecil dan Menengah (UMKM).

Berdasarkan hasil analisis data Hipotesis (Uji T) menunjukkan bahwa tingkat signifikansi variabel Pemberdayaan sebesar 0,049 lebih kecil dari 0,05 $(0,049<0,05)$ sehingga diketahui bahwa pemberdayaan berpengaruh positif dan signifikan terhadap kinerja UMKM yang ada di Kecamatan Pleret Kabupaten Bantul. Artinya semakin baik pemberdayaan pengusaha warung kelontong maka akan semakin baik pula kinerja UMKMnya dan semakin rendah pemberdayaan pengusaha warung kelontong maka akan semakin rendah pula kinerja UMKM yang berada di Kecamatan Pleret Kabupaten Bantul tersebut. Hal ini sesuai dengan tujuan pemberdayaan yang lainnya yaitu untuk menanggulangi masalah kemiskinan di dalam masyarakat.

b. Pengaruh Lama Mengelola Terhadap Kinerja Usaha Mikro, Kecil dan Menengah (UMKM).

Berdasarkan hasil analisis data Hipotesis (Uji T) menunjukkan bahwa tingkat signifikansi variabel Lama Mengelola sebesar 0,011lebih kecil dari 0,05 $(0,011<0,05)$ sehingga diketahui bahwa lama mengelola berpengaruh positif dan signifikan terhadap kinerja UMKM yang ada di Kecamatan Pleret Kabupaten Bantul. Artinya semakin lama mengelola yang dijalankan masyarakat sekitar maka akan semakin banyak pengalaman usaha yang akan dimiliki. Hal ini dikarenakan pengalaman usaha sangat diperlukan oleh seorang pengusaha. 
PUBLIK: Jurnal Manajemen Sumber Daya Manusia, Adminsitrasi dan Pelayanan Publik Sekolah Tinggi Ilmu Administrasi Bina Taruna Gorontalo Volume VIII Nomor 1, 2021

c. Pengaruh Pendapatan Terhadap Kinerja Usaha Mikro, Kecil dan Menengah (UMKM).

Berdasarkan hasil analisis data Hipotesis (Uji T) menunjukkan bahwa tingkat signifikansi variabel Pendapatan sebesar 0,000 lebih kecil dari 0,05 (0,000 $<0,05)$ sehingga diketahui bahwa pendapatan berpengaruh positif dan signifikan terhadap kinerja UMKM yang ada di Kecamatan Pleret Kabupaten Bantul. Dengan demikian, semakin tinggi pendapatan pengusaha warung kelontong maka akan semakin tinggi pula kinerja UMKMnya dan semakin rendah pendapatan pengusaha warung kelontong maka akan semakin rendah pula kinerja UMKM yang berada di Kecamatan Pleret Kabupaten Bantul tersebut. Semakin tinggi pendapatan UMKM maka semakin tinggi pula simpanan tabungan untuk masa depan yang akan dimiliki masyarakat tersebut.

d. Variabel Dominan

Berdasarkan hasil uji hipotesis pada tabel model persamaan (Hasil Analisis Regresi Berganda) menunjukkan bahwa variabel yang paling dominan berpengaruh terhadap Kinerja UMKM adalah Pendapatan, dapat dilihat dari kolom Unstandarized Coefficients $B$, menunjukkan bahwa Pendapatan memiliki angka yang paling tinggi $(0,832)$ dibandingkan dengan variabel lain. Maka dapat disimpulkan bahwa variabel yang paling dominan dalam penelitian ini adalah Pendapatan (X3).

\section{KESIMPULAN}

Berdasarkan analisis data dan hasil pengujian hipotesis pada penelitian ini dapat disimpulkan bahwa:

1. Pemberdayaan berpengaruh secara positif dan signifikan terhadap Kinerja UMKM karena tingkat signifikansi sebesar 0,049<0,05.

2. Lama Mengelola berpengaruh secara positif dan signifikan terhadap Kinerja UMKM karenatingkat signifikansi sebesar 0,011<0,05.

3. Pendapatan berpengaruh secara positif dan signifikan terhadap Kinerja UMKM karenatingkat signifikansi sebesar $0,000<0,05$.

4. Variabel yang paling dominan berpengaruh terhadap Kinerja UMKM adalah Pendapatan. Berdasarkan hasil uji hipotesis pada tabel model persamaan (Hasil Analisis Regresi Berganda) menunjukkan bahwa variabel yang paling dominan berpengaruhterhadap Kinerja UMKM adalah Pendapatan (X3), dapat dilihat dari 
PUBLIK: Jurnal Manajemen Sumber Daya Manusia, Adminsitrasi dan Pelayanan Publik Sekolah Tinggi Ilmu Administrasi Bina Taruna Gorontalo Volume VIII Nomor 1, 2021

kolom Unstandarized Coefficients $B$, menunjukkan bahwa Pendapatan (X3) memiliki angka yang paling tinggi $(0,832)$ di bandingkan dengan variabel lain.

\section{DAFTAR PUSTAKA}

Andiny, P., \& Nurjannah. (2018). Analisis Pemberdayaan Usaha Mikro Kecil dan Menengah (UMKM) sebagai upaya Penanggulangan Kemiskinan di Kota Langsa.Jurnal Serambi Ekonomi Dan Bisnis, 5(1), 31-37.

Maheswara, A. A. N. G., Setiawina, N. D., \& Saskara, I. A. N. (2016). Analisis FaktorFaktor Yang Mempengaruhi Pendapatan Ukm Sektor Perdagangan Di Kota Denpasar.E-Jurnal Ekonomi Dan Bisnis Universitas Udayana, 5(12), 4271-4298.

Polandos, P. M., Engka, D. S. M., Tolosang, K. D., Pembangunan, J. E., Ekonomi, F., \& Ratulangi, U. S. (2019). Analisis Pengaruh Modal, Lama Usaha, Dan Jumlah Tenaga Kerja Terhadap Pendapatan Usaha Mikro Kecil Dan Menengah Di Kecamatan Langowan Timur. Jurnal Berkala Ilmiah Efisiensi, 19(04), 36-47.

Sugiyono. (2017). Metode Penelitian Kuantitatif, Kualitatif, dan R\&D. Bandung : Alfabeta.

Wiyono, G. (2011). Merancang penelitian bisnis dengan alat analisis SPSS 17.0 \& SmartPLS 2.0.In Yogyakarta: UPP STIM YKPN. 